\title{
Identifying the robust economic, geographical and political determinants of FDI: an Extreme Bounds Analysis
}

\author{
Melisa Chanegriha ${ }^{1}$. Chris Stewart ${ }^{2}$. \\ Christopher Tsoukis ${ }^{3}$
}

Received: 31 March 2015 / Accepted: 4 April 2016 / Published online: 9 June 2016

(C) The Author(s) 2016. This article is published with open access at Springerlink.com

\begin{abstract}
Understanding what determines Foreign Direct Investment (FDI) inflows remains a primary concern of economists and policy makers; yet the uncertainty surrounding FDI theories and empirical approaches has created ambiguity regarding the determinants of FDI. This paper applies Extreme Bounds Analysis to identify the robust determinants of FDI using panel data covering 168 countries from 1970 to 2006 . We consider 58 potential economic, geographic and political determinants and find that almost one-third are robust, including: openness, education, government spending, corporate tax rate, infrastructure, experience of conflict, democratic governance, natural resources, geographic location, number of borders, coastal location and language.
\end{abstract}

We are grateful to Christopher Adock, Andrea Ingianni, Sushanta Mallick, Jonathan Temple, Yong Yang, participants at the GPEN-CGR conference, Queen Mary College, University of London (2013) and two anonymous referees of this Journal for helpful comments and suggestions.

\footnotetext{
$\triangle$ Christopher Tsoukis

c.tsoukis@keele.ac.uk

Melisa Chanegriha

m.chanegriha@mdx.ac.uk

Chris Stewart

c.stewart@kingston.ac.uk

1 Economics and International Development, Business School, Middlesex University, Hendon Campus, The Burroughs, London NW4 4BT, UK

2 School of Economics, History and Politics, Kingston University, Penrhyn Road, Kingston upon Thames, Surrey KT1 2EE, UK

3 Economics and Finance, Keele Management School, Keele University, Staffordshire ST5 5BG, UK
} 
Keywords Foreign Direct Investment · Extreme Bounds Analysis · Panel data · Economic, geographic and political determinants

JEL Classification F21 · C4

\section{Introduction}

Understanding what determines Foreign Direct Investment (FDI) remains a primary concern of economists and policy makers. However, the main determinants of FDI are still poorly understood because of the uncertainty and ambiguity surrounding both theories and empirical approaches to FDI. Given the sheer amount of possible determinants that theory and intuition suggest, it is not possible to nest all of them in a grand specification in a general-to-specific approach; thus, it is difficult to know which regressors are truly significant and which ones appear to be so as a result of omitted variable bias. "Extreme Bounds Analysis" (EBA), first developed by Leamer (1983, 1985) and Leamer and Leonard (1983), provides robustness and sensitivity tests of explanatory variables in regressions, in order to determine which regressors are robust and which are fragile. Widely applied in cross-country growth regressions, the procedure has not as yet found widespread application in the analysis of the determinants of FDI: As far as we are aware, only Chakrabarti (2001), Moosa and Cardak (2006) and Moosa (2009) have used EBA to identify the robust determinants of FDI.

This paper undertakes an exhaustive search for robust determinants of FDI by applying EBA, as developed by Sala-i-Martin (1997). We advance the literature on the determinants of FDI in several ways. First, we use a larger sample and a more comprehensive set of variables than in previous work on FDI. We include all possible determinants of FDI suggested by previous studies, which we group into two categories: "economic" and "geopolitical" country characteristics. In addition, the paper examines the role of geographical and institutional variables that have not been adequately explored in the current literature using the EBA method. Second, we use a panel data set, while previous applications of EBA (the three studies mentioned above) are only applied in a cross-section context; ours is the first study to apply EBA with a panel data set to the determinants of FDI. Third, this panel data set is one of the most extensive used in FDI analysis. We show that almost one-third of the previously suggested FDI determinants are robust. The next section outlines the EBA methodology and discusses the data and variables to be used in each EBA application. The results are discussed in Sect. 3, while Sect. 4 concludes the paper.

\section{Estimation methodology}

\subsection{The EBA approach}

Following standard practice in conducting EBA, we estimate Eq. (1). For each country $\mathrm{i}$, and each specific regression $\mathrm{jk}$ (where $j \in[1, M], k \in[1, K]$ as specified below), we have: 


$$
\left(\frac{\mathrm{FDI}}{Y}\right)_{i t}=\propto_{i j}+\boldsymbol{\beta}_{j k} \mathbf{X}_{i t}+\gamma_{j k} I_{k i t}+\boldsymbol{\delta}_{j k} \mathbf{Z}_{j i t}^{k}+\varepsilon_{i j t}
$$

where $\left(\frac{\mathrm{FDI}}{Y}\right)_{i}$ is FDI inflows as a percentage of GDP into country i. The explanatory variables on the right-hand side are divided in three groups: The first is $n$ standard ('core') explanatory variables that are included in every single regression (in addition to a constant) denoted $\mathbf{X}_{i t}=\left(\begin{array}{llll}X_{1 i t} & X_{2 i t} & \cdots & X_{n i t}\end{array}\right)$, where, $\boldsymbol{\beta}_{j k}=\left(\begin{array}{lllll}\beta_{1 k} & \beta_{2 k} & \cdots & \beta_{n k}\end{array}\right)^{\prime}$. Following Levine and Renelt (1992), we use a set of exactly three core variables, $\mathbf{X}_{i t}$, that are always kept in the equation. The second is $I_{k i t}$, which is the $k$ th variable of interest whose robustness we are testing and is a single variable selected from the set of variables $\mathbf{Z}_{i t}$, where the latter is a Kx1 vector containing all of the possible determinants of FDI that are not included in $\mathbf{X}_{i t}$. Following Leamer (1983), we consider all of the remaining variables in $\mathbf{Z}_{i t}$ (one at a time and each in turn) as $I_{k i t} . \mathbf{Z}_{i t}$ is identified from a wide range of past studies as including potentially important candidate determinants (beyond $\mathbf{X}_{i t}$ ) that need to be controlled for in FDI regressions. The third is $\mathbf{Z}_{j i t}^{k}$, which is a $3 \times 1$ vector of exactly three additional control variables chosen from the pool of possible (non-core) explanatory variables, $\mathbf{Z}_{i t}$, that do not include $I_{k i t}$. For each $k$, all the possible combinations of the remaining $K-1$ variables in the predetermined pool of variables $\mathbf{Z}_{i t}$ is considered; there are $M\left[=\frac{(K-1) !}{(K-1-3) ! \times 3 !}\right]$ such combinations. Further, $j=1,2, \ldots, M$, where $\mathrm{j}$ denotes the $j$ th estimated combination of the variables: the $j$ th model. The robustness of each variable of interest, $I_{k i t}$, is tested while controlling for $\mathbf{X}_{i t}$ and all the possible combinations $\mathbf{Z}_{j i t}^{k}$. Exactly three variables are included in $\mathbf{Z}_{j i t}^{k}$, partly to follow Sala-i-Martin's (1997) original methodology and also to avoid the perception of data mining or selective reporting of results. ${ }^{1}$ There are $M$ possible combinations for each of the $k=1,2, \ldots, K$ variables of interest, giving a total of $M \times K$ possible regressions. Finally, $\varepsilon_{i t}$ is an error term. The aim is to investigate the effects on the statistical significance of $\gamma_{j k}$, the coefficient on the $k$ th variable of interest, when varying the combinations of three variables included in $\mathbf{Z}_{j i t}^{k}$. The $(j=1,2, \ldots, M)$ estimated coefficients for each $I_{k i t}\left(\hat{\gamma}_{j k}\right)$ and $\mathbf{X}_{i t}\left(\hat{\boldsymbol{\beta}}_{j k}\right)$ are recorded. The standard deviation of these $M$ coefficient estimates is calculated for each $I_{k i t}$ and is denoted as $\hat{\sigma}_{k}$.

Sala-i-Martin's (1997) version of EBA, which we follow here, is based on the fraction of the cumulative distribution function (CDF) of $\hat{\gamma}_{j k}$ that lies to the right of zero. ${ }^{2}$ If this fraction is sufficiently large (small) for a positive (negative) relationship, $I_{k i t}$ is

\footnotetext{
1 We apply EBA with an intercept, the variable of interest, $I_{k i t}$, the same three core variables in all regressions, $\mathbf{X}_{i t}$, and allowing the $\mathbf{Z}_{j i t}^{k}$ variables to come in combinations of exactly three, giving seven explanatory variables plus an intercept in all estimated models. This follows almost all of the growth literature where at least seven explanatory variables are included in reported models. Fixing the number of regressors that appear in each regression has a direct effect on the size of the estimated coefficients (see Leon-Gonzalez and Montolio 2004) and it limits the number of the models that are explored.

2 In early versions of the test, Leamer $(1983,1985)$ and Leamer and Leonard (1983), a coefficient is robust if its Extreme Bounds (EB) are of the same sign. The EB are defined as: LowerEB $\equiv \hat{\gamma}_{k}^{\min }-2 \hat{\sigma}_{k}$ and UpperEB $\equiv \hat{\gamma}_{k}^{\max }+2 \hat{\sigma}_{k}$, where $\hat{\gamma}_{k}^{\max }$ and $\hat{\gamma}_{k}^{\min }$ are the highest and lowest values of $\hat{\gamma}_{j k}$, respectively. In our case, unsurprisingly, no variables showed up as robust according to this very restrictive criterion.
} 
regarded as robust: specifically, if more than $90 \%$ (less than $10 \%$ ) of the CDF for $\hat{\gamma}_{j k}$ is above zero, $I_{k i t}$ is robust. We apply two variants of Sala-i-Martin's (1997) EBA, being the normal and non-normal CDF methods. Sala-i-Martin's method involves the calculation of a CDF for each variable of interest, $I_{k i t}$, using the $(j=1,2, \ldots, M)$ estimated coefficients, $\hat{\gamma}_{j k}$, and estimated coefficient variances, $\hat{\sigma}_{j k}^{2}$. Using these values the mean of $\hat{\gamma}_{j k}$ is constructed as the average of each of the $\mathrm{M} \hat{\gamma}_{j k}$, thus, $\bar{\gamma}_{k}=\sum_{j=1}^{M} \frac{1}{M} \hat{\gamma}_{j k}{ }^{3}$ Similarly, the average of the coefficient variances are $\bar{\sigma}_{k}^{2}=\sum_{j=1}^{M} \frac{1}{M} \hat{\sigma}_{j k}^{2} \cdot{ }^{4}$ Assuming the $\gamma_{j k}$ have a standard normal distribution across the M models, the CDF is evaluated at zero as $\Phi\left(0 \mid \bar{\gamma}_{k}, \bar{\sigma}_{k}^{2}\right)$, where $\Phi$ denotes the cumulative density based on the standard normal distribution. Finally, the $\operatorname{CDF}(0)$ statistics indicates the larger of the areas under the density function either side of zero [hence $0.5 \leq \operatorname{CDF}(0) \leq 1$ ], that is:

$$
\begin{array}{ll}
\operatorname{CDF}(0)=\Phi\left(0 \mid \bar{\gamma}_{k}, \bar{\sigma}_{k}^{2}\right) & \text { if } \Phi\left(0 \mid \bar{\gamma}_{k}, \bar{\sigma}_{k}^{2}\right) \geq 0.5 \\
\operatorname{CDF}(0)=1-\Phi\left(0 \mid \bar{\gamma}_{k}, \bar{\sigma}_{k}^{2}\right) & \text { if } \Phi\left(0 \mid \bar{\gamma}_{k}, \bar{\sigma}_{k}^{2}\right)<0.5
\end{array}
$$

According to Sala-i-Martin (1997), if the $\gamma_{j k}$ are not normally distributed across the $\mathrm{M}$ models for any particular $k, \mathrm{CDF}(0)$ can be calculated using the individual $\mathrm{CDF}$ for each of the $\mathrm{M}$ regressions. The $\mathrm{CDF}$ for the $j$ th regression is denoted as: $F_{j}\left(0 \mid \hat{\gamma}_{j k}, \hat{\sigma}_{j k}^{2}\right)$ where:

$$
\begin{array}{ll}
F_{j}\left(0 \mid \hat{\gamma}_{j k}, \hat{\sigma}_{j k}^{2}\right)=\Phi_{j}\left(0 \mid \hat{\gamma}_{j k}, \hat{\sigma}_{j k}^{2}\right) & \text { if } \Phi_{j}\left(0 \mid \hat{\gamma}_{j k}, \hat{\sigma}_{j k}^{2}\right) \geq 0.5 \\
F_{j}\left(0 \mid \hat{\gamma}_{j k}, \hat{\sigma}_{j k}^{2}\right)=1-\Phi_{j}\left(0 \mid \hat{\gamma}_{j k}, \hat{\sigma}_{j k}^{2}\right) & \text { if } \Phi_{j}\left(0 \mid \hat{\gamma}_{j k}, \hat{\sigma}_{j k}^{2}\right)<0.5
\end{array}
$$

The aggregate "non-normal" $\mathrm{CDF}$, denoted $\operatorname{CDF}(0)^{*}$, is calculated as the average of the $(j=1,2, \ldots, M)$ individual CDFs (3), thus:

$$
\operatorname{CDF}(0)^{*}=\frac{1}{M} \sum_{j=1}^{M} F_{j}\left(0 \mid \hat{\gamma}_{j k}, \hat{\sigma}_{j k}^{2}\right)
$$

Variables are regarded as robust when both CDFs are at least 0.90 . The degree of robustness is assigned as follows: robust at the $1 \%$ level when $\mathrm{CDF}(0) \geq 0.99$ or $\mathrm{CDF}(0)^{*} \geq 0.99$ (which is denoted with $* * *$ ), robust at the $5 \%$ level when either

\footnotetext{
3 We are careful to exclude regressions where the regressions do not estimate.

4 Note that because of a missing data problem, we do not attach different weights to different models' parameters. Furthermore, the integrated likelihood (which has been suggested as a weight) may not be a good indicator of the probability that a model is the true model (see Sala-i-Martin 1997). For these reasons, we are unable to use the extension of this approach called Bayesian Averaging of Classical Estimates (BACE), introduced by Sala-i-Martin et al. (2004). We have also not followed Granger and Uhlig's (1990) criterion whereby regressions are included if their $R^{2}$ is higher than a threshold, or otherwise discarded; the dual reason is the arbitrariness of the threshold and the 'knife-edge' nature of the criterion (e.g., a regression would fully count if its $R^{2}=0.6$ - say-but be completely discarded if $R^{2}=0.59$ ).
} 
$\mathrm{CDF} \geq 0.95(* *)$, robust at the $10 \%$ level when both $\mathrm{CDF} \geq 0.90(*) .{ }^{5}$ A variable is regarded as a "fragile" determinant of FDI otherwise. ${ }^{6}$

We carry out two applications of the EBA procedure: firstly using only economic variables (results reported in Sect. 3.1) and then augmenting the dataset with the inclusion of political and geographic variables (Sect. 3.2). In the first of these applications, we test all possible variables considered in both $\mathbf{X}_{i t}$ and $\mathbf{Z}_{i t}$ for robustness. In all applications, we report the results based on Sala-i-Martin's (1997) method assuming both normal and non-normal CDFs (cf. 2 and 4 respectively).

\subsection{Data}

We consider 58 potential economic, political and geographical explanatory factors. ${ }^{7}$ The definitions of the variables used are given in Table 1. Data were constructed from a number of sources, including World Development Indicators 2006 (World Bank 2006). The political and institutional variables are obtained from the International Country Risk Guide (ICRG), and we construct the geographical dummy variables. Our sample is an unbalanced annual panel dataset for 168 economies over the period 1970-2006.

\subsection{Estimation issues}

Our first application of EBA that considers only economic determinants employ the fixed-effects estimator in all regressions; this is so as it is more likely to ensure consistent estimates than the random-effects estimator. ${ }^{8}$ However, the random-effects estimator is employed in our second EBA application that incorporates economic, geographical and political variables because some of these variables are perfectly collinear with the (cross-sectional) fixed-effects.

A potential problem for our estimates is endogeneity, which causes OLS estimators to be biased and inconsistent. We identify three potential determinants as being the most likely to be endogenously determined with FDI as the current account balance (\% of GDP-CAB), GDP growth (GDPG) and per-capita GDP (GDPP). ${ }^{9}$ We therefore treat $\mathrm{CAB}$, GDPG and GDPP as potentially endogenous in our EBA applications because the costs of incorrectly treating exogenous variables as endogenous are much lower than incorrectly assuming endogenous variables are exogenous. This means that these three variables are excluded from $\mathbf{X}_{i t}$ and $\mathbf{Z}_{i t}$ in all EBA applications and are

\footnotetext{
5 We take 0.90 as the posterior probability threshold following Sala-i-Martin (1997) and Fernandez et al. (2001).

${ }^{6}$ Exactly the same procedure is applied to (and statistics reported for) the coefficient estimates $\hat{\boldsymbol{\beta}}_{j k}$ in our first EBA application.

7 See Chakrabarti (2001, Table 1) and ODI (1997) for detailed discussions of empirical findings on the determinants of FDI. Table 1 in his paper indicates how ambiguous the evidence is.

${ }^{8}$ Application of the Hausman test and $F$ test in initial modelling suggested the use of the fixed-effects estimator.

9 To confirm endogeneity we applied the Wu-Hausman test based upon a fixed-effects estimated example regression. The results, available upon request, suggest failure of weak exogeneity for these variables.
} 


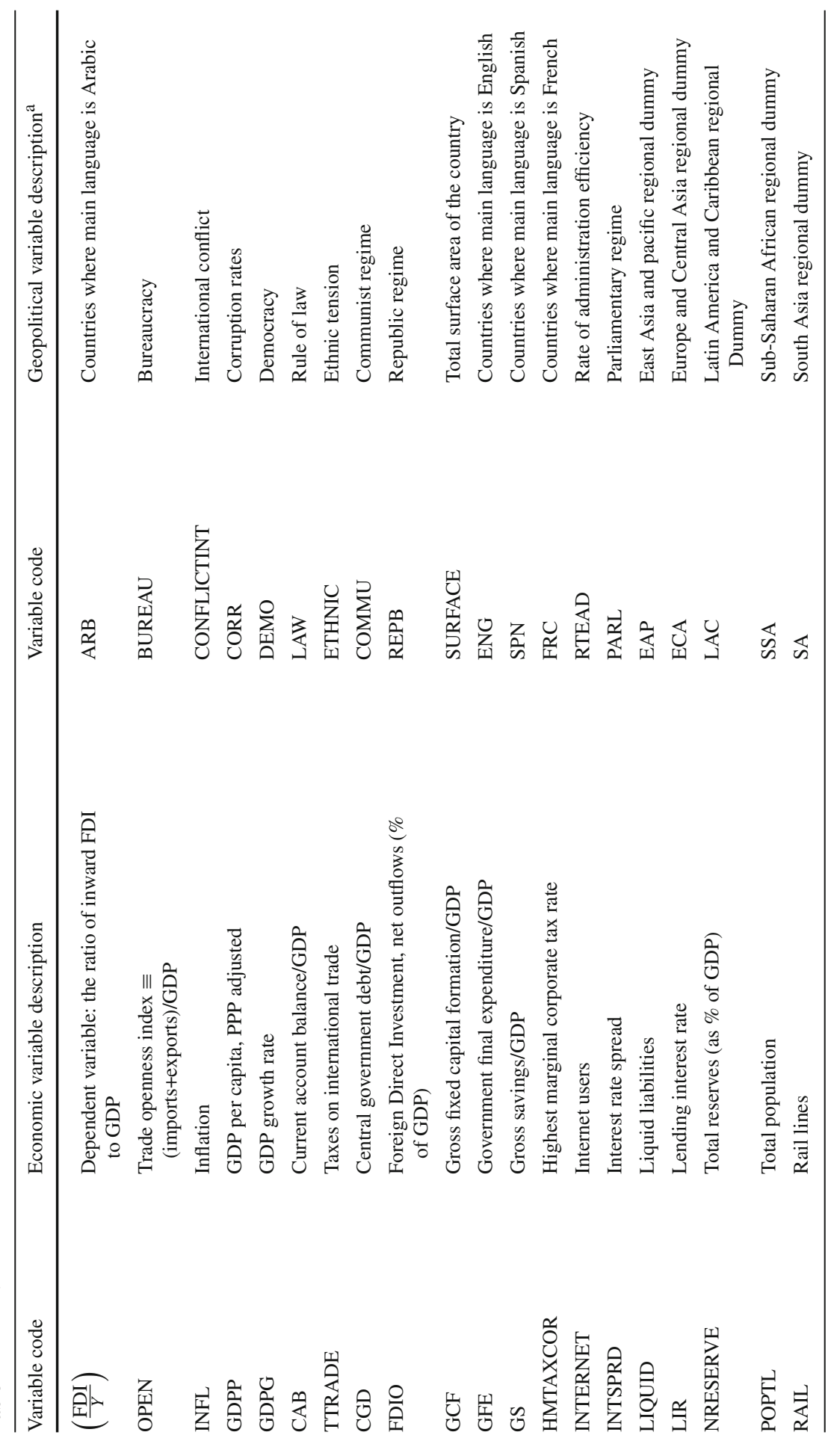




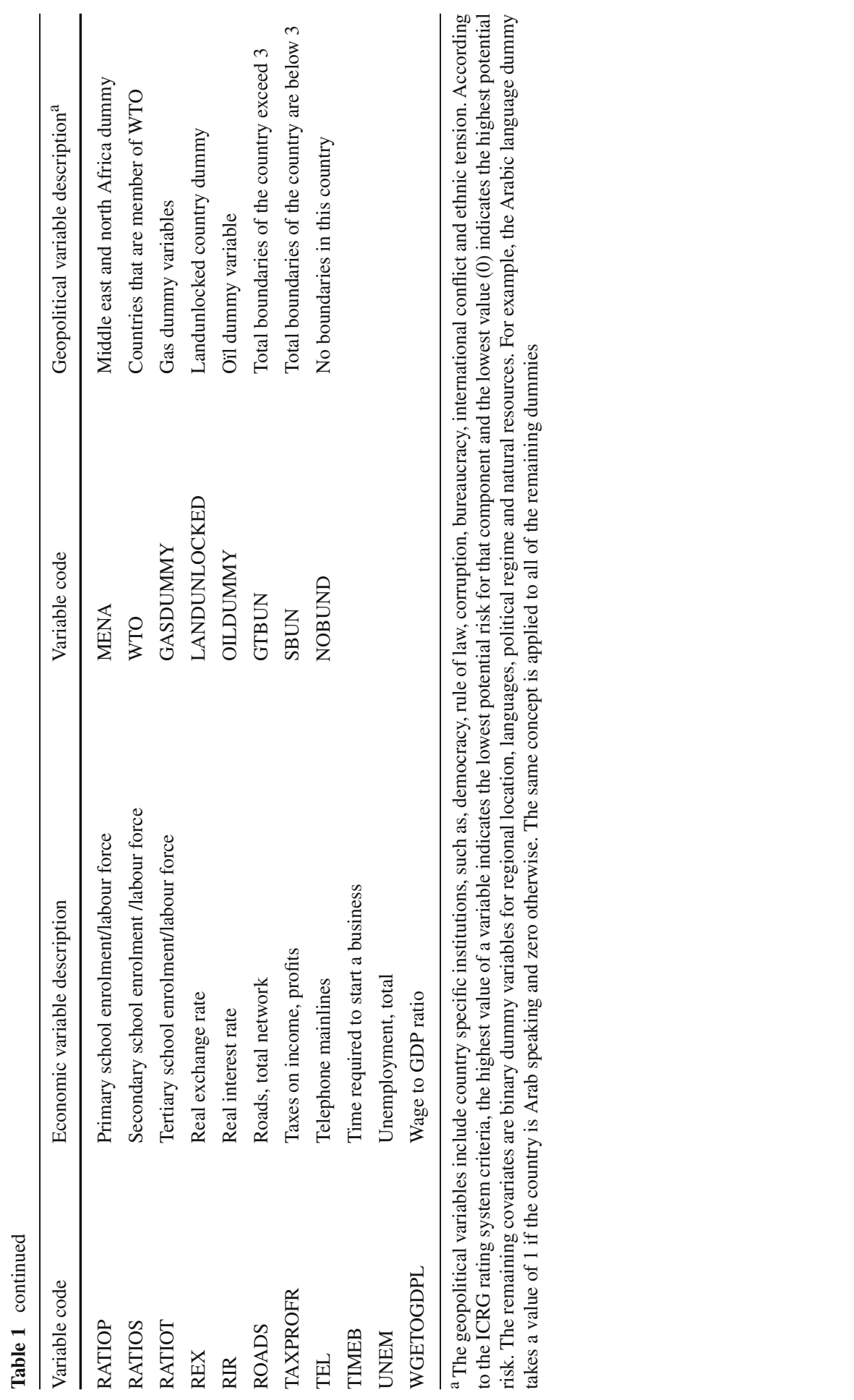


only considered as $I_{k i t}$ variables. Hence, the only inference that could be affected by endogeneity bias is when these covariates are considered as the variable of interest.

\section{Results}

This section presents the empirical results of our two EBA applications. In Sect. 3.1, we discuss the results of the EBA applied only to economic variables; in Sect. 3.2, we discuss the EBA application involving economic, political and geographical variables.

\subsection{EBA using only economic variables}

The 30 potential economic determinants of FDI that we consider in our first EBA application are listed in the left-hand side of Table 1. The following three core variables, $\mathbf{X}_{i t}$, that are always kept in the equation are: openness (denoted OPEN), inflation (INFL), and tax on trade (TTRADE). These core variables are chosen because they have been shown to be robustly linked to FDI in previous empirical work (as well as in our initial experiments), and we do not expect them to be endogenous. All of the remaining 27 economic determinants are considered as the variable of interest, $I_{k i t}$; however, only 24 of these are included in $\mathbf{Z}_{j i t}^{k}$ because we are seeking to minimise the impact of any endogeneity bias that the current account balance (CAB), GDP growth (GDPG) and per-capita GDP (GDPP) variables may cause. ${ }^{10}$

Tables 2, 3, 4, 5 summarise the results of our first EBA application. The first column reports the variable of interest under consideration. For each $I_{k i t}$ variable four sets of EBA statistics are reported: one set for the $I_{k i t}$ variable (reported in Table 5) and one set for each of the 3 core variables: OPEN (Table 2), INFL (Table 3) and TTRADE (Table 4). ${ }^{11}$ Some models cannot be estimated due to insufficient observations, and this causes some variation in the number of regressions run for the different $I_{k i t}$.

The column headed "AVG coeft" gives the variable's coefficient averaged over the number of regressions used in the EBA application. Sala-i-Martin's (1997) non-normal $\mathrm{CDF}$ [denoted $\left.\mathrm{CDF}(0)^{*}\right]$ and normal $\mathrm{CDF}[\mathrm{CDF}(0)]$ statistics are also reported in the tables. Bold emphasis indicates that a variable is robust based upon Sala-i-Martin's criteria. For a variable to be robust, it must have a CDF of at least 0.90 according to both normal and non-normal criteria (the normal and non-normal CDF broadly yield the same inference); otherwise, the variable is said to be fragile.

Table 2 indicates that the core variable, Trade openness index (OPEN), is robust in 26 out of 27 sets of EBA results (the exception is when TIMEB is the variable of interest). This result is consistent with many previous studies that found openness towards trade to be a significant determinant of FDI (e.g. Chakrabarti 2001; Moosa

\footnotetext{
${ }^{10}$ In our first EBA application, the variables in $\mathbf{Z}_{i t}$ have pairwise correlation coefficients that are (in all cases) below 0.5 in magnitude. This should limit the problem of multicollinearity which can adversely affect conclusions regarding robustness.

11 In Tables 2, 3, 4, each core variable is tested for robustness with the test results specified in a disaggregated form for each of the non-core variables. In contrast, Table 5 assesses the robustness of the non-core variables of interest, $I_{k i t}$.
} 
Table 2 First EBA application with only economic variables_results for Open
The first column (headed " $I_{k i t}$ ") reports the variable of interest used in the EBA application and the results relate to the core variable OPEN. "AVG coeft" represents each $I_{k i t}$ variable's coefficient averaged over the number regressions used in the EBA application.

Sala-i-Martin's (1997) non-normal $\mathrm{CDF}$ is denoted "CDF $(0)$ * and the normal CDF is " $\mathrm{CDF}(0)$ ". Bold emphasis indicates that a variable is robust (otherwise it is fragile) based upon Sala-i-Martin's criteria. $* * *$ denotes robustness at the 0.99 level, $* *$ at the 0.95 level and $*$ at the 0.90 level

\begin{tabular}{|c|c|c|c|}
\hline$I_{k i t}$ & AVG coeft. & $\operatorname{CDF}(0)^{*}$ & $\mathrm{CDF}(0)$ \\
\hline GDPP & $0.059 * * *$ & 0.986 & 0.999 \\
\hline GDPG & $0.053 * * *$ & 0.983 & 0.997 \\
\hline CAB & $0.063 * * *$ & 0.990 & 0.992 \\
\hline CGD & $0.914 * * *$ & 0.994 & 1.000 \\
\hline FDIO & $0.056 * * *$ & 0.993 & 0.998 \\
\hline GCF & $0.057 * * *$ & 0.990 & 0.999 \\
\hline GFE & $0.059 * * *$ & 0.992 & 1.000 \\
\hline GS & $0.063 * * *$ & 0.992 & 0.999 \\
\hline HMTAXCOR & $0.108 * * *$ & 0.984 & 0.998 \\
\hline INTERNET & $0.073 * * *$ & 0.994 & 1.000 \\
\hline INTRESPRD & $0.064 * * *$ & 0.991 & 0.999 \\
\hline LIQUID & $0.031 * *$ & 0.906 & 0.951 \\
\hline LIR & $0.062 * * *$ & 0.993 & 0.999 \\
\hline NRESERVE & $0.053 * *$ & 0.929 & 0.972 \\
\hline POPTL & $0.069 * * *$ & 0.985 & 0.998 \\
\hline RAIL & $0.072 * * *$ & 0.981 & 0.996 \\
\hline RATIOP & $0.069 * * *$ & 0.982 & 0.997 \\
\hline RATIOS & $0.068 * * *$ & 0.980 & 0.995 \\
\hline RATIOT & $0.057 * * *$ & 0.987 & 0.999 \\
\hline REX & $0.155^{* * * *}$ & 0.952 & 1.000 \\
\hline RIR & $0.062 * * *$ & 0.992 & 0.999 \\
\hline ROADS & $0.044 * *$ & 0.951 & 0.980 \\
\hline TAXPROFR & $0.061 * * *$ & 0.991 & 0.999 \\
\hline TEL & $0.057 * * *$ & 0.958 & 1.000 \\
\hline TIMEB & 0.020 & 0.672 & 0.607 \\
\hline UNEM & $0.091 * * *$ & 0.999 & 1.000 \\
\hline WGETOGDL & $0.061 * * *$ & 0.988 & 0.999 \\
\hline
\end{tabular}

and Cardak 2006). In all 27 cases, OPEN has an average coefficient sign ("AVG coeft") that is positive which is consistent with theoretical expectations. From Table 3, the INFL core variable is robust in only one (RATIOT) of the 27 EBA sets and is a fragile determinant for the remaining $26 I_{k i t}$. The TTRADE core variable is robust in only one (CGD) of the 27 EBA sets and is a fragile determinant otherwise, see Table 4. This is considered as strong evidence against TTRADE and INFL being robust determinants of FDI.

From Table 5 we see that eight non-core variables are unambiguously robust determinants of FDI because both of their CDFs exceed 0.90. These are current account balance (CAB), GDP growth rate (GDPG), GDP per capita (GDPP), highest marginal corporate tax rate (HMTAXCOR), outgoing FDI (FDIO), tertiary and secondary school enrolment (RATIOT and RATIOS, resp.) and Government final expenditure (GFE). The negative and robust coefficient of HMTAXCOR suggests that high corpo- 
Table 3 First EBA application with only economic variables-results for Infl
The first column (headed " $I_{k i t}$ ") reports the variable of interest used in the EBA application and the results relate to the core variable INFL. All other labels are defined as in Table 2. Bold emphasis indicates that a variable is robust (otherwise it is fragile) based upon

Sala-i-Martin's criteria. *** denotes robustness at the 0.99 level, $* *$ at the 0.95 level and * at the 0.90 level

\begin{tabular}{|c|c|c|c|}
\hline $\mathbf{I}_{\text {kit }}$ & AVG coeft. & $\operatorname{CDF}(0)^{*}$ & $\operatorname{CDF}(0)$ \\
\hline GDPP & -0.003 & 0.806 & 0.623 \\
\hline GDPG & -0.001 & 0.764 & 0.524 \\
\hline $\mathrm{CAB}$ & -0.003 & 0.813 & 0.605 \\
\hline CGD & -0.011 & 0.631 & 0.705 \\
\hline FDIO & -0.003 & 0.813 & 0.574 \\
\hline GCF & -0.002 & 0.797 & 0.571 \\
\hline GFE & -0.003 & 0.766 & 0.608 \\
\hline GS & -0.002 & 0.789 & 0.568 \\
\hline HMTAXCOR & -0.013 & 0.699 & 0.579 \\
\hline INTERNET & -0.001 & 0.837 & 0.827 \\
\hline INTRESPRD & -0.005 & 0.770 & 0.624 \\
\hline LIQUID & -0.007 & 0.832 & 0.827 \\
\hline LIR & -0.003 & 0.768 & 0.606 \\
\hline NRESERVE & -0.015 & 0.793 & 0.665 \\
\hline POPTL & -0.004 & 0.793 & 0.570 \\
\hline RAIL & -0.002 & 0.749 & 0.526 \\
\hline RATIOP & 0.001 & 0.770 & 0.524 \\
\hline RATIOS & -0.005 & 0.748 & 0.775 \\
\hline RATIOT & $-0.020 * *$ & 0.909 & 0.962 \\
\hline REX & -0.013 & 0.766 & 0.779 \\
\hline RIR & -0.004 & 0.598 & 0.656 \\
\hline ROADS & -0.004 & 0.812 & 0.570 \\
\hline TAXPROFR & -0.002 & 0.784 & 0.586 \\
\hline TEL & -0.004 & 0.805 & 0.583 \\
\hline TIMEB & 0.141 & 0.808 & 0.807 \\
\hline UNEM & -0.010 & 0.814 & 0.684 \\
\hline WGETOGDL & -0.005 & 0.611 & 0.682 \\
\hline
\end{tabular}

rate taxes in the host country will have a robust negative effect on FDI, in line with the finding of Becker and Fuest (2012). Government expenditure as a proportion of GDP (GFE) is also robust and has, on average, a negative sign, validating the critics of government (see e.g. Mitchell 2005; Sinn 1995). The tertiary enrolment ratio (RATIOT) and secondary enrolment ratio (RATIOS) are both found to be robust determinants of FDI with generally positive coefficients, which are consistent with previous literature and implies that education attracts FDI. ${ }^{12}$ FDI outflows (FDIO) is another robust determinant of FDI inflows. This could be because the multinational corporations (MNCs) of developing countries may be both the recipients of incoming FDI and originators of outgoing FDI; thus, FDI and FDIO may be positively correlated. Both GDPG and

\footnotetext{
12 See for instance the theoretical analysis of Lucas (1993) and the empirical findings of Zhang and Markusen (1999), Dunning (1988) and Noorbakhsh and Paloni (2001).
} 
Table 4 First EBA application with only economic variables-results for Ttrade
The first column (headed "I $I_{k i t}$ ") reports the variable of interest used in the EBA application and the results relate to the core variable TTRADE. All other labels are defined as in Table 2 . Bold emphasis indicates that a variable is robust (otherwise it is fragile) based upon

Sala-i-Martin's criteria. *** denotes robustness at the 0.99 level, ** at the 0.95 level and * at the 0.90 level

\begin{tabular}{|c|c|c|c|}
\hline$I_{k i t}$ & AVG coeft. & $\mathrm{CDF}(0)^{*}$ & $\mathrm{CDF}(0)$ \\
\hline GDPP & -0.002 & 0.736 & 0.712 \\
\hline GDPG & -0.001 & 0.754 & 0.503 \\
\hline $\mathrm{CAB}$ & -0.008 & 0.747 & 0.754 \\
\hline CGD & $0.696 * * *$ & 0.956 & 1.000 \\
\hline FDIO & 0.002 & 0.756 & 0.616 \\
\hline GCF & 0.003 & 0.764 & 0.718 \\
\hline GFE & 0.009 & 0.758 & 0.560 \\
\hline GS & 0.002 & 0.750 & 0.510 \\
\hline HMTAXCOR & 0.034 & 0.665 & 0.636 \\
\hline INTERNET & 0.046 & 0.764 & 0.739 \\
\hline INTRESPRD & 0.014 & 0.770 & 0.581 \\
\hline LIQUID & -0.010 & 0.775 & 0.563 \\
\hline LIR & 0.013 & 0.750 & 0.577 \\
\hline NRESERVE & -0.006 & 0.744 & 0.522 \\
\hline POPTL & 0.040 & 0.670 & 0.694 \\
\hline RAIL & 0.005 & 0.759 & 0.520 \\
\hline RATIOP & 0.034 & 0.715 & 0.659 \\
\hline RATIOS & 0.047 & 0.723 & 0.668 \\
\hline RATIOT & 0.007 & 0.752 & 0.744 \\
\hline REX & 0.155 & 0.824 & 0.894 \\
\hline RIR & 0.013 & 0.753 & 0.579 \\
\hline ROADS & 0.058 & 0.766 & 0.779 \\
\hline TAXPROFR & -0.007 & 0.757 & 0.544 \\
\hline TEL & 0.063 & 0.845 & 0.854 \\
\hline TIMEB & -0.088 & 0.675 & 0.598 \\
\hline UNEM & 0.078 & 0.807 & 0.812 \\
\hline WGETOGDL & 0.028 & 0.740 & 0.653 \\
\hline
\end{tabular}

GDPP robustly and positively affect FDI. As these are measures of future prospects and market size and demand, this finding is consistent with theoretical expectations; however, we cannot rule out bi-directional causality. Additionally, we find that the current account balance $(\mathrm{CAB})$ affects FDI, the negative sign is consistent with theory; however, bi-directional or even reverse causality cannot be ruled out. In sum, all of the nine robust variables (OPEN, GFE, FDIO, RATIOS, RATIOT, CAB, GDPG, GDPP, HMTAXCOR) have theoretically plausible (average) coefficient signs. However, we treat the finding of robustness for the three potentially endogenous variables $\mathrm{CAB}$, GDPG and GDPP with caution and hesitate to conclude that our results offer strong support for it.

Apart from these nine variables, all of the other variables in our first EBA application are fragile. Comparing our findings with previous applications of EBA to FDI provides interesting insights. Moosa and Cardak (2006) found telephone mainlines 
Table 5 First EBA application with only economic variables-results for $\mathbf{I}_{\mathbf{k i t}}$
The first column (headed " $I_{k i t}$ ") reports the variable of interest used in the EBA application and the results relate to $I_{k i t}$. All other labels are defined as in Table 2. Bold emphasis indicates that a variable is robust (otherwise it is fragile) based upon Sala-i-Martin's criteria. *** denotes robustness at the 0.99 level, ** at the 0.95 level and $*$ at the 0.90 level

\begin{tabular}{|c|c|c|c|}
\hline$I_{k i t}$ & AVG coeft. & $\mathrm{CDF}(0)^{*}$ & $\mathrm{CDF}(0)$ \\
\hline GDPP & $0.004 * *$ & 0.939 & 0.981 \\
\hline GDPG & $0.078 *$ & 0.917 & 0.931 \\
\hline $\mathrm{CAB}$ & $-0.123 * * *$ & 0.995 & 0.999 \\
\hline HMTAXCOR & $-0.157 * *$ & 0.940 & 0.981 \\
\hline FDIO & $0.055^{*}$ & 0.905 & 0.922 \\
\hline GCF & 0.057 & 0.835 & 0.817 \\
\hline GFE & $-0.174 * * *$ & 1.000 & 0.940 \\
\hline RATIOT & $0.018 * *$ & 0.987 & 0.950 \\
\hline RATIOS & $0.355 * * *$ & 0.995 & 1.000 \\
\hline INTERNET & -0.001 & 0.764 & 0.636 \\
\hline INTRESPRD & 0.019 & 0.753 & 0.679 \\
\hline LIQUID & 0.010 & 0.680 & 0.648 \\
\hline LIR & -0.004 & 0.751 & 0.579 \\
\hline NRESERVE & $1.8 \times 10^{-12}$ & 0.682 & 0.544 \\
\hline POPTL & 0.008 & 0.749 & 0.558 \\
\hline RAIL & 0.001 & 0.679 & 0.600 \\
\hline RATIOP & -0.019 & 0.742 & 0.660 \\
\hline CGD & -0.005 & 0.700 & 0.585 \\
\hline GS & $4.03 \times 10^{-12}$ & 0.733 & 0.718 \\
\hline REX & -0.015 & 0.720 & 0.715 \\
\hline RIR & -0.007 & 0.713 & 0.596 \\
\hline ROADS & $3.46 \times 10^{-7}$ & 0.645 & 0.563 \\
\hline TAXPROFR & -0.041 & 0.840 & 0.842 \\
\hline TEL & 0.004 & 0.805 & 0.835 \\
\hline TIMEB & -0.025 & 0.760 & 0.741 \\
\hline UNEM & -0.104 & 0.744 & 0.771 \\
\hline WGETOGDL & 0.180 & 0.841 & 0.818 \\
\hline
\end{tabular}

to be robust, whereas we find it to be fragile in this application; however, we do find it to be a robust determinant in the next application when we consider both geopolitical and economic variables. Further, Moosa and Cardak found GDP growth and tertiary education enrolments to be fragile, while we find these variables to be robust. Chakrabarti (2001) found openness to be robust as we do, though not GDP growth.

\subsection{EBA using economic, geographical and political variables}

In our second EBA application, we include OPEN, GFE and RATIOS as our core variables following the results of our first EBA. OPEN is chosen because it is the only core variable from our first EBA application that is robust. Since the other two core variables (INFL and TTRADE) are not robust in our first EBA application, we seek 
two different core variables; those should, firstly, be robust with an average coefficient sign that is consistent with theoretical expectations in the first EBA application and that have the highest value for $\operatorname{CDF}(0)^{*}$; secondly, they must not be amongst the 3 potentially endogenous variables. The three variables with the highest values for $\operatorname{CDF}(0)^{*}$ are GFE $\left(\operatorname{CDF}(0)^{*}=1.00\right)$, RATIOS $(0.95)$ and $\mathrm{CAB}(0.95)$. Since we regard $\mathrm{CAB}$ as potentially endogenous, we select the other 2 as core variables, along with OPEN, to be employed in our second EBA application.

We add 28 geographical and political variables (described on the right-hand side of Table 1) to the economic variables to be considered in the second EBA application, allowing us to test the robustness of an extended set of variables. The geopolitical variables are not included in the core set of variables, $\mathbf{X}_{i t}$, or the set of three $\mathbf{Z}_{j i t}^{k}$ variables (to help avoid multicollinearity); however, they are all considered (in turn) as the variable of interest, $I_{k i t}$. All of the economic variables (except the three core variables) are considered (in turn) as $I_{k i t}$ and in $\mathbf{Z}_{j i t}^{k}$ (except for the potentially endogenous variables, CAB, GDPG and GDPP, and the three core variables). ${ }^{13}$ The focus in this second application is to determine whether country specific institutions (such as democracy, rule of law, corruption, bureaucracy, ethnic and international conflict and type of political regime), ${ }^{14}$ cultural factors (languages) or geographical locations (number of boundaries, coastal location, abundance of natural resources, proximity to particular regions) can influence FDI. Many geographical and political/institutional factors have been conclusively linked to economic growth (e.g., Durlauf et al. 2005) and remain active areas of research. The results of our second EBA application are reported in Table 6.

Ten of the 28 geopolitical variables are considered as robust determinants of FDI as both of their CDFs are at least 0.90. These include the dummies for: countries in the South Asia region (SA), countries in the East Asia and Pacific region (EAP), countries with more than 3 boundaries (GTBUN), countries that are not land-locked (LANDUNLOCKED), Spanish (SPN)- and Arabic (ARB)-speaking countries as well as nations with greater democratic accountability (DEMO). These seven determinants are all generally positively correlated with FDI inflows. The other three robust geopolitical variables are dummies for countries experiencing low international and internal conflict (CONFLICTINT) and economies with an abundance of the natural resources: oil (OILDUMMY) and gas (GASDUMMY). ${ }^{15}$ These three determinants are all generally negatively correlated with FDI inflows.

DEMO is a robust determinant with a generally positive coefficient sign, which is expected as democracy increases transparency and reduces arbitrariness and red

\footnotetext{
13 The maximum number of regressions estimated in the first and second EBA applications are 48,576 and 98,164, respectively. However we only obtain results from 15,148 and 85,369 regressions, respectively. Thus, in the two EBA applications, we estimated 146,740 models and obtain results from 100,517.

14 Political and other institutions are a vibrant area of research in growth theory and empirics (see e.g. Easterly and Levine 2003; Glaeser et al. 2004; and Durlauf et al. 2005).

15 Our results also show that the SSA (Sub-Saharan African region) and MENA (Middle East and North Africa) dummies are fragile determinants of FDI. One plausible explanation is the weak institutions in these regions.
} 
Table 6 Second EBA application with economic and geopolitical variables $-\mathbf{I}_{\mathbf{k i t}}$ results

\begin{tabular}{|c|c|c|c|c|c|c|c|}
\hline$I_{k i t}$ & AVG coeft. & $\operatorname{CDF}(0)^{*}$ & $\mathrm{CDF}(0)$ & $I_{k i t}$ & AVG coeft. & $\mathrm{CDF}(0)^{*}$ & $\mathrm{CDF}(0)$ \\
\hline $\mathrm{ARB}$ & $16.223 * * *$ & 0.97 & 1.00 & FDIO & $0.733 * * *$ & 0.985 & 1.000 \\
\hline SA & $19.505 * * *$ & 0.98 & 1.00 & CGD & $0.696 * * *$ & 0.983 & 1.000 \\
\hline LANDUNLOCKED & $0.696^{* * * *}$ & 0.95 & 1.000 & CAB & $-0.123 * * *$ & 0.995 & 0.999 \\
\hline SPN & $0.953 * *$ & 0.965 & 0.961 & INTERNET & $0.010 * *$ & 0.984 & 0.988 \\
\hline GTBUN & $1.162 * *$ & 0.98 & 0.950 & GDPP & $0.004 * *$ & 0.939 & 0.981 \\
\hline EAP & $4.371 *$ & 0.90 & 0.92 & RATIOT & $-5.718 * *$ & 0.907 & 0.950 \\
\hline DEMO & $0.340 *$ & 0.90 & 0.91 & TEL & $0.010 *$ & 0.919 & 0.944 \\
\hline CONFLICTINT & $-0.216^{* *}$ & 0.95 & 0.90 & GDPG & $0.078 *$ & 0.917 & 0.931 \\
\hline OILDUMMY & $-3.332 *$ & 0.94 & 0.90 & LIQUID & 0.011 & 0.841 & 0.892 \\
\hline GASDUMMY & $-3.213^{*}$ & 0.93 & 0.90 & $\mathrm{GCF}$ & 0.161 & 0.870 & 0.869 \\
\hline PARL & -1.240 & 0.83 & 0.85 & TAXPROFR & -0.041 & 0.840 & 0.842 \\
\hline LAW & -1.189 & 0.88 & 0.85 & POPTL & 0.196 & 0.814 & 0.800 \\
\hline ECA & 2.494 & 0.81 & 0.80 & HMTAXCOR & -0.202 & 0.744 & 0.771 \\
\hline ENG & -2.039 & 0.81 & 0.78 & RIR & 0.017 & 0.583 & 0.716 \\
\hline SBUN & 1.944 & 0.74 & 0.77 & REX & -0.020 & 0.722 & 0.715 \\
\hline SSA & -2.040 & 0.77 & 0.76 & UNEM & 0.069 & 0.753 & 0.691 \\
\hline REPB & 0.127 & 0.77 & 0.72 & TTRADE & -0.021 & 0.753 & 0.684 \\
\hline MENA & -1.747 & 0.70 & 0.67 & INTRESPRD & 0.019 & 0.753 & 0.679 \\
\hline ETHNIC & -0.093 & 0.77 & 0.66 & ROADS & $8.509 \times 10^{-7}$ & 0.647 & 0.649 \\
\hline NOBUND & -1.269 & 0.70 & 0.64 & NRESERVE & $5.989 \times 10^{-11}$ & 0.708 & 0.626 \\
\hline SURFACE & $1.8 \times 10^{-7}$ & 0.63 & 0.62 & WGETOGDL & -8.698 & 0.726 & 0.591 \\
\hline LAC & 0.847 & 0.75 & 0.61 & LIR & 0.004 & 0.696 & 0.579 \\
\hline RTEAD & 0.007 & 0.675 & 0.598 & RAIL & $7.076 \times 10^{-6}$ & 0.655 & 0.574 \\
\hline BUREAU & 0.187 & 0.60 & 0.58 & GS & $-4.309 \times 10^{-13}$ & 0.670 & 0.568 \\
\hline FRC & 0.563 & 0.72 & 0.56 & TIMEB & -0.002 & 0.787 & 0.562 \\
\hline WTO & -0.898 & 0.74 & 0.56 & INFL & -0.005 & 0.668 & 0.560 \\
\hline CORR & 0.030 & 0.70 & 0.54 & RATIOP & $3.939 \times 10^{-5}$ & 0.610 & 0.504 \\
\hline COMMU & 0.166 & 0.64 & 0.52 & & & & \\
\hline
\end{tabular}

The column headed " $I_{k i t}$ " reports the variable of interest used in the EBA application and the results relate to $I_{k i t}$. All other labels are defined as in Table 2. Bold emphasis indicates that a variable is robust (otherwise it is fragile) based upon Sala-i-Martin's criteria. *** denotes robustness at the 0.99 level, $* *$ at the 0.95 level and $*$ at the 0.90 level

tape (Jensen 2008 and Li 2009). ${ }^{16}$ The internal and external conflict variable (CONFLICTINT) is robust with a generally negative coefficient sign. This is consistent with a priori expectations as less conflict reduces incertitude amongst potential investors,

\footnotetext{
16 However, Asiedu and Lien (2011) find that democracy attracts FDI in countries where the share of natural resources in total exports is low, but has a negative effect on FDI in countries where exports are dominated by natural resources. This statement may to some extent explain why we did not find the SSA and MENA regions as robust determinants of FDI (the countries in these regions have weak democracy and their exports are dominated by natural resources—see the previous Footnote).
} 
which raises FDI. Hence, our results support the notion that an increase in institutional quality (as indicated by greater democracy and lower conflict) would strengthen incoming FDI; these results are consistent with previous analyses (e.g. Globerman and Shapiro 2002; Sachs 2003). It is noteworthy that various other variables whose relevance has been highlighted in the theory of growth, such as rule of law, corruption, bureaucracy, ethnic conflict or type of political regime, are fragile determinants of FDI.

Our results also suggest that language is an important factor in attracting FDI. We found that countries where Arabic and Spanish are the main language have higher incoming FDI ceteris paribus. This result may be driven by the higher incoming FDI into countries such as the Middle East and Latin America, as opposed to others in Africa and elsewhere in which English or French are the official languages; dummies representing countries where English and French are the main language are found to be fragile. International languages such as English and to some extent French may play a role in attracting FDI, but they are often spoken by much of the population in countries where they are not the main language and this may help explain why countries where English and French are the main languages do not receive any significant increases in incoming FDI. We also find that coastal countries tend to attract more FDI: the dummy "LANDUNLOCKED", indicating countries that are not landlocked, is a robust determinant with a generally positive sign. This is consistent with findings in growth empirics (Easterly and Levine 2003). Furthermore, countries with more than three boundaries attract more FDI than those with fewer boundaries given the robust and generally positive coefficient. This is also in the spirit of the previous finding (the "landunlocked" feature): a country with more neighbours has more freedom to trade and, hence, better prospects for incoming FDI. While "landlockedness" has been emphasised in the past as a factor affecting growth and FDI, the finding that the numbers of borders affects FDI is, we believe, novel.

Natural resource abundance in the form of oil and gas (OILDUMMY and GASDUMMY, respectively) are both found to be robust determinants of FDI with generally negative coefficient signs. This is a kind of "Dutch disease", akin to that highlighted by Sachs and Warner (1995) in relation to growth; see also Tietenberg and Lewis (2006). This reasoning will of course not apply to specifically resource-seeking firms, which would naturally be attracted by resource abundance; this would explain the inflows of FDI into the Arab Gulf and African countries. All other geopolitical variables exert only a fragile influence on FDI.

From Table 6 we see that eight non-core economic variables are robust determinants of FDI: CAB, GDPG, GDPP, CGD, FDIO, INTERNET, RATIOT and TEL. These findings for economic variables are similar to those in Table 5 in that FDIO, RATIOT, CAB, GDPG and GDPP are found to be robust in both of our EBA applications-broadly confirming the robustness of these results. For economic variables, the average coefficient signs are the same in Tables 6 and 5 except for RATIOT which has a generally negative coefficient sign in Table 6; this change in coefficient sign between the two EBA applications may be due to RATIOS being a core variable in the second application and not the first. Table 6 suggests three additional robust economic variables, which are central government debt (CGD), internet use (INTERNET) and telephone mainline use (TEL). CGD appears as robust with a generally negative coefficient: this is expected, as debt may have a number of adverse consequences, such as inducing 
higher interest rates and raising default risk. The latter two capture communication facilities. As expected an increase in internet and telephone use increases FDI inflows, as indicated by the generally positive coefficient signs for these variables. All of the other economic variables in our second EBA application are fragile.

\section{Conclusion}

We investigate the determinants of incoming Foreign Direct Investment (FDI) using Extreme Bounds Analysis (EBA) to address the issue of model uncertainty. We employ an unbalanced panel dataset covering 168 countries over the period 1970 to 2006 . We consider 58 economic, geographical and political variables that have been previously proposed as determinants of FDI. As far as we are aware, this is the largest set of variables and the largest coverage of data in any analysis of the determinants of FDI. Our EBA application to FDI further extends previous work in its use of a large panel dataset instead of just cross-sectional data which previous EBA analyses employ and by the inclusion of political and geographical factors as well as economic variables. In these respects we believe our work significantly extends the existing literature that seeks to understand the determinants of FDI. We use Sala-i-Martin's (1997) EBA approach to carry out two analyses: one with only economic variables using the fixedeffects estimator, and one that includes all our variables (economic, political and geographic) employing random-effects to avoid collinearity.

In our first EBA application that only considers economic determinants, we find that the following six variables (excluding the three potentially endogenous covariates) have a robust relationship (with average coefficient signs that are consistent with theoretical expectations) according to both of Sala-i-Martin's Cumulative Distribution Function (CDF) criteria: Trade openness index, outgoing FDI, Government final expenditure (\% of GDP), highest marginal corporate tax rate, tertiary and secondary school enrolment. However, the three variables current account balance, GDP growth rate and GDP per capita are robust if potentially subject to problems of endogeneity. Based upon this, we use Trade openness, Government final expenditure and the secondary school enrolment variables as the core variables in our second EBA application that considers both economic and geopolitical determinants of FDI.

According to both of Sala-i-Martin's (1997) CDF criteria, our second EBA application reveals that 18 of the 55 (non-core) variables are robust determinants of FDI. There are ten robust geopolitical determinants that suggest the following relations with inward FDI. Countries located in South Asia, East Asia and the pacific region, that have more than 3 boundaries, that are not land-locked, that are Spanish or Arabic speaking, that have greater democratic accountability and that experience less conflict attract more FDI. Natural resource abundance (in terms of oil and gas) has a negative impact on FDI. Additionally, excluding the three potentially endogenous variables, there are four robust (non-core) economic determinants of inward FDI in the second application whose average coefficient signs are consistent with theoretical expectations; these are Central Government debt, outgoing FDI, number of Internet users, and number of Telephone lines. Tertiary school enrolment is robust; however, it has an unexpected average coefficient sign. Together with the three core variables, these 
are our final list of robust determinants: The above ten geopolitical determinants, five economic determinants, plus the three core variables that are considered robust on the basis of the first application. All other variables are deemed fragile. These results are generally consistent with previous analyses and prior arguments.

Our study has important implications for policies aimed at promoting FDI and, therefore, economic development. Openness suggests the need for governments to maintain economies open to international trade, fostering competition and innovation. Education at secondary and tertiary levels suggests the need for human capital to be promoted and skills and labour productivity more broadly to be developed. Government expenditures generally crowd out resources from the private sector; hence, government spending is robust and negatively related to incoming FDI. ${ }^{17}$ At the same time, the need to maintain orderly public finances is highlighted by the presence of government debt, which is robustly negative; this is so as higher debt implies, ceteris paribus, higher future taxes. The role of this variable has not been highlighted in previous literature, although it plays a prominent role in public discourse. Internet usage and number of telephone lines are variables that signify both a developed internal market and a developed infrastructure. The role of government policy in maintaining the former was highlighted above; at the same time, government, in association with the private sector, also has a critical role to play in enhancing the latter. Furthermore, business taxation is important in maintaining a thriving business environment and here is another important role for government policy. Our results suggest that economic institutions and their quality matter in attracting FDI: democratic governance, avoidance of conflict as well as openness promote profitability, investment and incoming FDI. More broadly, institutional quality and quality of governance matters, as has been repeatedly affirmed in the context of growth analyses. Thus, we find a role for government policies with relevance at different horizons, from the short term (government spending, taxation) to the medium term (education, infrastructure) to the long term (taxation again, orderly public finances, institutional quality). In all, incoming FDI is considered as a key part of the process of development; our study identifies its key determinants and highlights several which leave a critical role to be played by government policy for their promotion.

Open Access This article is distributed under the terms of the Creative Commons Attribution 4.0 International License (http://creativecommons.org/licenses/by/4.0/), which permits unrestricted use, distribution, and reproduction in any medium, provided you give appropriate credit to the original author(s) and the source, provide a link to the Creative Commons license, and indicate if changes were made.

\section{References}

Asiedu E, Lien D (2011) Democracy FDI and natural resources. J Int Econ 84:99-111. doi:10.1016/j. jinteco.2010.12.001

Becker JC, Fuest C, Riedel N (2012) Corporate tax effects on the quality and quantity of FDI. Eur Econ Rev 56:1495-1511. doi:10.1016/j.euroecorev.2012.07.001

\footnotetext{
17 This finding suggests that in countries with large government sectors such as the industrialised ones, there will be, ceteris paribus, a net outflow of FDI.
} 
Chakrabarti A (2001) The determinants of foreign direct investment: sensitivity analyses of cross-country regressions. Kyklos 54:89-114. doi:10.1111/1467-6435.00142

Dunning JH (1988) The eclectic paradigm of international production: a restatement and some possible extensions. J Int Bus Stud 19:1-31. doi:10.1057/palgrave.jibs.8490372

Durlauf S, Johnson PA, Temple JRW (2005) Growth econometrics, Chapter 8. In: Aghion P, Durlauf S (eds) Handbook of economic growth. North-Holland, Amsterdam

Easterly W, Levine R (2003) Tropics germs and crops: how endowments influence economic development. J Monet Econ 50:3-39. doi:10.1016/S0304-3932(02)00200-3

Fernandez C, Ley E, Steel MFJ (2001) Model uncertainty in cross-country growth regressions. J Appl Econom 16:563-576

Glaeser EL, LaPorta R, Lopez-de-Silanes F, Shleifer A (2004) Do institutions cause growth? J Econ Growth 9:271-303. doi:10.1023/B:JOEG.0000038933.16398.ed

Globerman S, Shapiro D (2002) Global foreign direct investment flows: the role of governance infrastructure. World Dev 30:1899-1919. doi:10.1016/S0305-750X(02)00110-9

Granger CWJ, Uhlig H (1990) Reasonable extreme bound analysis. J Econom 44:159-170. doi:10.1016/ 0304-4076(90)90077-7

ICRG (various years) International Country Risk Guide The PRS Group. https:/www.prsgroup.com/ about-us/our-two-methodologies/icrg

Jensen NM (2008) Political risk democratic institutions and foreign direct investment. J Politics 70:10401052. doi:10.1017/S0022381608081048

Leamer EE (1983) Let's take the con out of econometrics. Am Econ Rev 73:31-43

Leamer EE (1985) Sensitivity analysis would help. Am Econ Rev 75:308-313

Leamer EE, Leonard H (1983) Reporting the fragility of regression estimates. Rev Econ Stat 65:306-17. doi: $10.2307 / 1924497$

Leon-Gonzalez R, Montolio D (2004) Growth convergence and public investment a Bayesian model averaging approach. Appl Econ 36:1925-1936. doi:10.1080/0003684042000245534

Levine R, Renelt D (1992) A sensitivity analysis of cross-country growth regressions. Am Econ Rev 82:942-963

Li Q (2009) Democracy autocracy and expropriation of foreign direct investment. Comp Political Stud 42:1098-1127. doi:10.1177/0010414009331723

Lucas RE (1993) On the determinants of foreign direct investment: evidence from East and Southeast Asia. World Dev 21:391-406. doi:10.1016/0305-750X(93)90152-Y

Mitchell DJ (2005) The impact of government spending on economic growth national heritage foundation. http://www.heritage.org/research/reports/2005/03/the-impact-of-government-spendingon-economic-growth

Moosa IA (2009) The determinants of foreign direct investment in MENA countries: an extreme bounds analysis. Appl Econ Lett 16:1559-1563. doi:10.1080/13504850701578819

Moosa IA, Cardak B (2006) The determinants of foreign direct investment: an extreme bounds analysis. J Multinatl Financ Manag 16:199-211. doi:10.1016/j.mulfin.2005.07.002

Noorbakhsh F, Paloni A (2001) Human capital and FDI inflows to developing countries: new empirical evidence. World Dev 29:1593-1610. doi:10.1016/S0305-750X(01)00054-7

ODI: Overseas Development Institute (1997) Foreign direct investment flows to low-income countries: a review of the evidence. https://www.odi.org/sites/odi.org.uk/files/odi-assets/ publications-opinion-files/2626.pdf

Sachs J (2003) Institutions don't rule: direct effects of geography on per capita income NBER working paper no 9490

Sachs J, Warner A (1995) Natural resource abundance and economic growth NBER working paper No 5398

Sala-i-Martin X (1997) I just ran two million regressions. Am Econ Rev 87:178-183

Sala-i-Martin X, Doppelhofer G, Miller R (2004) Determinants of long term growth: a Bayesian averaging of classical estimates (BACE) approach. Am Econ Rev 94:813-835. doi:10.1257/0002828042002570

Sinn H-W (1995) A theory of the welfare state. Scand J Econ 97:495-526

Tietenberg T, Lewis L (2006) Environmental and natural resource economics, 5th edn. Pearson, Upper Saddle River

World Bank (2006) World development indicators. http://data.worldbank.org/products/data-books/ WDI-2006

Zhang K, Markusen K (1999) Vertical multinationals and host-country characteristics. J Dev Econ 59:233252. doi:10.1016/S0304-3878(99)00011-5 